\title{
Bc MANDICA - NOVA Bc SORTA OZIME PŠENICE
}

\author{
R. MLINAR, I. IKIĆ, Katarina JUKIĆ, M. MARIČEVIĆ, M. BUKAN \\ Bc Institut za oplemenjivanje i proizvodnju bilja d.d., \\ Bc Institute for Breeding and Production of Field Crops
}

\begin{abstract}
SAŽETAK
Bc Institut d.d. iz Zagreba u svoj proizvodni program uključio je novu visokorodnu sortu ozime pšenice pod imenom Bc Mandica. Sorta botanički pripada vrsti Triticum aestivum L. emend Fiori et Paol., ima bijeli glatki klas bez osja, zrno crvene boje te spada u varijetet Lutscens Al. Tijekom provedenih istraživanja u svrhu priznavanja prosječni urod novopriznate sorte u službenim pokusima Hrvatskog centra za poljoprivredu, hranu i selo Zavoda za sjemenarstvo i rasadničarstvo iznosio je $8.438 \mathrm{~kg} / \mathrm{ha} \mathrm{i} \mathrm{nadmašio} \mathrm{je}$ sve standardne pšenice, Srpanjku, Žitarku i Divanu. Nakon uspješno provedenog ispitivanja, 2014. godine upisana je na Sortnu listu Republike Hrvatske. Sorta Bc Mandica pripada grupi srednje ranih sorti, ostvaruje stabilan i izuzetno visok urod zrna, a po pokazateljima kvalitete zrna, brašna i tijesta, sorta Bc Mandica svrstana je u B1 grupu kvalitete.
\end{abstract}

Ključne riječi: pšenica, sorta, urod zrna, kvaliteta

\section{UVOD}

Prva sorta ozime pšenice s oznakom Bc selekcije, Vuka, priznata je 1964. godine (Potočanac, 1966). Od tada su timovi istraživača Bc Instituta za oplemenjivanje i proizvodnju bilja d.d. kreirali veliki broj sorti koje se uspješno uzgajaju u Republici Hrvatskoj, kao i u državama okruženja. Zahvaljujući uspješnom programu oplemenjivanja, Bc Institut je prepoznat kao izvoznik kvalitetnog sjemena brojnih ratararskih kultura (kukuruz, tritikale, ječam, pir) kao i sorti pšenice. U početku, prioritetni oplemenjivački ciljevi bili su visoka rodnost i stabilnost uroda, dobra kvaliteta, otpornost na niske temperature, polijeganje te stabljičnu i crnu rđu (Borojević i Potočanac, 1966; Borojević, 1986). Tek osamdesetih godina prošlog stoljeća javlja se naglašenija potreba za pekarskom kakvoćom (Jošt i sur., 2006). Suvremeni koncept oplemenjivanja pšenice u Bc Institutu d.d. osigurava kontinuirano stvaranje novih sorti s poboljšanim svojstvima (Tomasović i sur., 2012). Da bi nova sorta imala visok genetski potencijal rodnosti, a uz to još i stabilan proizvodni potencijal, treba dobro kombinirati nasljednu bazu odgovornu za otpornost na niske temperature, ranozrelost, otpornost na polijeganje, sušu, osipanje, tolerantnost na važnije bolesti, dobru fertilnost klasa te krupno i dobro naliveno zrno. Opisana sortna svojstva uz primjenu intenzivne agrotehnike i korištenje certificiranog sjemena mogu 
R. Mlinar i sur: Bc Mandica - nova sorta ozime pšenice

osigurati pozitivnu ekonomsku računicu u proizvodnji pšenice. Cilj ovog rada je temeljem rezultata egzaktnih pokusa upoznati stručnu javnost s novopriznatom sortom ozime pšenice $\mathrm{Bc}$ Mandica.

\section{MATERIJAL I METODE RADA}

$\mathrm{Za}$ analizu su korišteni rezultati istraživanja ozimih selekcija pšenice postignuti u mreži pokusa Hrvatskog centra za poljoprivredu, hranu i selo - Zavoda za sjemenarstvo i rasadničarstvo. Provedenim VCU i DUS ispitivanjima utvrđena je gospodarska vrijednost te različitost, ujednačenost i stabilnost sorte. Kemijske i tehnološke analize sorte provedene su 2012. godine u akreditiranom laboratoriju, ispitivanjem uzoraka zrna sa lokacija Zagreb i Osijek. Za predstavljanje sorte korišteni su i rezultati sortnih pokusa Bc Instituta d.d. s lokacija Botinec, Rugvica i Staro Topolje, te rezultati laboratorijskog ispitivanja kvalitete Bc Instituta.

\section{REZULTATI I RASPRAVA}

Kao početni materijal za stvaranje nove sorte korištena je linija 187-188 i sorta Feniks. Novopriznata sorta Bc Mandica je rezultat križanja domaćih genotipova (Tablica 1).

Tablica 1. Postupak stvaranja i registracije nove sorte ozime pšenice Bc Mandica

Table 1. Development and registration of the new winter wheat variety Bc Mandica

\begin{tabular}{|c|c|c|}
\hline Generacija / Generation & Oplemenjivački postupak / Breeding procedure & Sezona / Season \\
\hline 1 & $\begin{array}{l}\text { Izbor roditelja i hibridizacija } \\
\text { Choice of parents and hybridization } \\
187188^{1}, \text { Feniks }^{2}\end{array}$ & 2002. \\
\hline $2-6$ & $\begin{array}{l}\text { Izbor u cijepajucim generacijama } \\
\text { Selection in the segregating generations }\end{array}$ & $\begin{array}{l}2002 . / 2003 . \\
2006 . / 2007 .\end{array}$ \\
\hline 7 & $\begin{array}{l}\text { Preliminarni sortni pokus } \\
\text { Preliminary testing }\end{array}$ & 2007./2008. \\
\hline $8-9$ & $\begin{array}{l}\text { Komparativni sortni pokusi } \\
\text { Comparative testing }\end{array}$ & $\begin{array}{l}2008 . / 2009 . \\
2009 . / 2010 .\end{array}$ \\
\hline 10 & $\begin{array}{l}\text { Pokusi na više lokacija } \\
\text { Multi-environmental testing }\end{array}$ & 2010./2011. \\
\hline $11-12$ & $\begin{array}{l}\text { Ispitivanja u Komisiji za priznavanje, test kvalitete } \\
\text { State variety trials for registration, quality tests }\end{array}$ & $\begin{array}{l}2011 . / 2012 . \\
2012 . / 2013\end{array}$ \\
\hline 12 & $\begin{array}{l}\text { Godina priznavanja } \\
\text { Year of registration }\end{array}$ & 2013. \\
\hline 13 & $\begin{array}{l}\text { Proizvodnja izvornog sjemenskog materijala } \\
\text { Foundation seed preparation }\end{array}$ & 2013./2014. \\
\hline $14>$ & $\begin{array}{l}\text { Distribucija certificiranog sjemena } \\
\text { Distribution of certified seed }\end{array}$ & 2014./2015.> \\
\hline
\end{tabular}

Porijeklo: ${ }^{1}$ Agronomski fakultet Sveučilišta u Zagrebu, ${ }^{2}$ Poljoprivredni institut Osijek

Origin: ' University of Zagreb, Faculty of Agriculture, ${ }^{2}$ Agricultural Institute Osijek 
R. Mlinar i sur: Bc Mandica - nova sorta ozime pšenice

Hibridizacija je izvršena 2002. godine s ciljem da se u novoj sorti kombiniraju pozitivna svojstava odabranih roditelja. U generacijama cijepanja selekcija je rađena pedigre metodom. Nakon višegodišnjeg ispitivanja nova je selekcija pod šifrom Bc 8204/07 prijavljena Komisiji za priznavanje sorti Republike Hrvatske.

\section{Morfološka svojstva}

Sorta Bc Mandica ima bijeli gladak klas bez osja, sa zrnom crvene boje. U klasu formira 21 - 25 klasića, s 3 - 4 zrna u klasiću. Klas je srednje dužine, dosta kompaktan, u punoj zrelosti ostaje uglavnom uspravan. Stabljika je čvrsta i elastična, u prosjeku visine $85 \mathrm{~cm}$. Lišće je srednje široko, tamnozelene boje, poluuspravno u odnosu na stabljiku (Tablica 2).

Tablica 2. Agronomska svojstva sorte pšenice Bc Mandica - prosječne vrijednosti lokacija Botinec, Rugvica, Županja, 2009./2010. i Botinec, Rugvica, Staro Topolje, 2010./2011.

Table 2 Agronomic traits of the new wheat variety Bc Mandica-mean values for Botinec, Rugvica, Županja 2009/2010 and Botinec, Rugvica, StaroTopolje 2010/2011

\begin{tabular}{lc}
\hline Svojstva / Traits & $\begin{array}{c}\text { Sorta/variety } \\
\text { Bc Mandica }\end{array}$ \\
\hline $\begin{array}{l}\text { Klasanje (broj dana od 01. siječnja do klasanja) } \\
\text { Heading, days from January } 1 \text { st }\end{array}$ & 138 \\
\hline $\begin{array}{l}\text { Visina biljke }(\mathrm{cm}) \\
\text { Plant height }(\mathrm{cm})\end{array}$ & 85 \\
\hline $\begin{array}{l}\text { Polijeganje }(\%) \\
\text { Lodging }(\%)\end{array}$ & 10 \\
\hline $\begin{array}{l}\text { Masa } 1000 \mathrm{zrna}(\mathrm{g}) \\
\text { l.000 kernel weight }(\mathrm{g})\end{array}$ & 40,6 \\
\hline $\begin{array}{l}\text { Hektolitarska masa }(\mathrm{kg} / \mathrm{hl}) \\
\text { Test weight }(\mathrm{kg} / \mathrm{hl})\end{array}$ & 74,1 \\
\hline $\begin{array}{l}\text { Urod zrna }(\mathrm{kg} / \mathrm{ha}) \\
\text { Grain yield }(\mathrm{kg} / \mathrm{ha})\end{array}$ & 8.362 \\
\hline $\begin{array}{l}\text { Relativni urod, 2010. } \\
\text { Relative yield, } 2010 \\
\text { (Sana+Žitarka+Soissons+Renan) / } 4=(100 \%)\end{array}$ & 111,3 \\
\hline $\begin{array}{l}\text { Relativni urod, 2011. } \\
\text { Relative yield, } 2011 \text { (Lucija+Žitarka+Soissons+Renan) } / 4=(100 \%)\end{array}$ & 122,5 \\
\hline
\end{tabular}

\section{Fiziološka svojstva}

Bc Mandica pripada grupi srednje ranih sorti. Klasanje je oko četiri dana kasnije od standardne sorte Žitarka. Ne osipa se, tako da podnosi i kasnije rokove žetve. Sorta je tolerantna na najvažnije gljivične bolesti pa lišće dugo zadržava zelenu boju i fotosintetsku aktivnost. Uz visoku otpornost prema niskim temperaturama sorta se odlikuje i brzom proljetnom regeneracijom. Ima osrednji potencijal produktivnog busanja. Osnovne i bitne karakteristike sorte iskazane su DUS ocjenama (Tablica 3). 
R. Mlinar i sur: Bc Mandica - nova sorta ozime pšenice

Tablica 3. Svojstva sorte Bc Mandica uključena u UPOV vodič, Izvješće Zavoda za sjemenarstvo i rasadničarstvo, Osijek

Table 3 Characteristics of $\mathrm{cv}$. Bc Mandica included in the UPOV Test Guideline, Final report of the Institute for seed and seedlings, Osijek

\begin{tabular}{|c|c|c|}
\hline $\begin{array}{c}\text { Svojstva } \\
\text { Characteristics }\end{array}$ & $\begin{array}{l}\text { Stupanj ekspresije } \\
\text { State of Expression }\end{array}$ & $\begin{array}{c}\text { Ocjena } \\
\text { Note }\end{array}$ \\
\hline $\begin{array}{l}\text { Tip busanja } \\
\text { Plant growth habit }\end{array}$ & $\begin{array}{l}\text { polu-uspravno do prijelazno } \\
\text { Semi-erect to intermediate }\end{array}$ & 4 \\
\hline $\begin{array}{l}\text { Frekvencija biljaka s povijenim listom zastavičarom } \\
\text { Frequency of plants with recurved flag leaves }\end{array}$ & $\begin{array}{c}\text { niska } \\
\text { low }\end{array}$ & 3 \\
\hline $\begin{array}{l}\text { Vrijeme klasanja (prvi klasići vidljivi na } 50 \% \text { klasova) } \\
\text { Time of ear emergence }\end{array}$ & $\begin{array}{l}\text { srednje } \\
\text { medium }\end{array}$ & 5 \\
\hline $\begin{array}{l}\text { Visina biljke (stabljika, klas, osje i produžeci pljevica) } \\
\text { Plant height (stem, ear, awns and scurs) }\end{array}$ & $\begin{array}{l}\text { kratka do srednja } \\
\text { short to medium }\end{array}$ & 4 \\
\hline $\begin{array}{l}\text { Forma klasa u profilu } \\
\text { Ear shape in profile }\end{array}$ & $\begin{array}{l}\text { Fusiform } \\
\text { fusiform }\end{array}$ & 5 \\
\hline $\begin{array}{l}\text { Zbijenost klasa } \\
\text { Ear density }\end{array}$ & $\begin{array}{l}\text { rijedak do srednji } \\
\text { lax to medium }\end{array}$ & 4 \\
\hline $\begin{array}{l}\text { Duljina klasa (bez osja ili produžetka pljevica) } \\
\text { Ear lenght (excluding awns and scurs) }\end{array}$ & $\begin{array}{l}\text { Srednja } \\
\text { medium }\end{array}$ & 5 \\
\hline $\begin{array}{l}\text { Osje ili produžetak pljevica: prisutnost } \\
\text { Awns or scurs: presence }\end{array}$ & $\begin{array}{l}\text { prisutni produžeci pljevica } \\
\text { scurs present }\end{array}$ & 2 \\
\hline $\begin{array}{l}\text { Boja klasa } \\
\text { Ear colour }\end{array}$ & $\begin{array}{l}\text { bijela } \\
\text { white }\end{array}$ & 1 \\
\hline $\begin{array}{l}\text { Boja zrna } \\
\text { Grain colour }\end{array}$ & $\begin{array}{l}\text { crvena } \\
\text { red }\end{array}$ & 1 \\
\hline $\begin{array}{l}\text { Sezonalni tip } \\
\text { Seasonal type }\end{array}$ & $\begin{array}{c}\text { ozimi tip } \\
\text { winter type }\end{array}$ & 1 \\
\hline
\end{tabular}

\section{Produktivna svojstva}

Urod zrna kao kvantitativno svojstvo dosta je izložen djelovanju okoline. Da bi se provjerile produktivne karakteristike sorte, ispitivanja se moraju provoditi više godina i na više lokacija. Urod sorte Bc Mandica i elementi rodnosti ispitivani su na pokusnim poljima Bc Instituta 2010. godine na lokacijama Botinec, Rugvica i Županja, te 2011. godine na lokacijama Botinec, Rugvica i Staro Topolje. Urod zrna novopriznate sorte u prvoj godini ispitivanja bio je veći od ukupnog prosjeka standardnih pšenica (Sana, Žitarka, Soissons i Renan) za 11,3\%. Naredne, 2011. godine, Bc Mandica je postigla veći urod od standardnih pšenica Lucije, Žitarke, Soissona i Renana za 22,5\% (Tablica 2).

$\mathrm{Na}$ osnovi rezultata pokusa Komisije za priznavanje (Tablica 4), nova sorta imala je prosječan urod zrna $8.438 \mathrm{~kg} / \mathrm{ha}$. 
R. Mlinar i sur: Bc Mandica - nova sorta ozime pšenice

Tablica 4. Urod zrna (kg/ha) sorte pšenice Bc Mandica u usporedbi sa standardnim sortama - prosječne vrijednosti lokacija: Tovarnik, Osijek, Kutjevo i Zagreb (Pokusi Komisije za priznavanje sorata Republike Hrvatske)

Table 4 Grain yield $(\mathrm{kg} / \mathrm{ha}$ ) of the variety Bc Mandica in relation to standard varieties - average values at locations: Tovarnik, Osijek, Kutjevo and Zagreb. (Experiments of the Croatian Committee for Registration of Agricultural Crop Varieties)

\begin{tabular}{|c|c|c|c|c|c|c|}
\hline \multirow{2}{*}{$\begin{array}{l}\text { Sorta } \\
\text { Variety }\end{array}$} & \multicolumn{2}{|c|}{$\begin{array}{l}\text { Godina ispitivanja } \\
\text { Year of investigations }\end{array}$} & \multirow{2}{*}{$\begin{array}{c}\text { Prosjek } \\
\text { Mean } \\
(\mathrm{kg} / \mathrm{ha})\end{array}$} & \multicolumn{3}{|c|}{$\begin{array}{c}\text { Relativno - Relative } \\
(\%)\end{array}$} \\
\hline & 2012. & 2013. & & Srpanjka & Žitarka & Divana \\
\hline Bc Mandica & 9.289 & 7.587 & 8.438 & 126,2 & 119,0 & 140,0 \\
\hline Srpanjka & 7.974 & 5.388 & 6.681 & 100 & & \\
\hline Žitarka & 7.659 & 6.511 & 7.085 & & 100 & \\
\hline Divana & 7.133 & 4.918 & 6.025 & & & 100 \\
\hline $\begin{array}{l}\text { Prosjek- } \\
\text { mean }\end{array}$ & 8.014 & 6.101 & & & & \\
\hline
\end{tabular}

Rezultati su dobiveni na osnovi ispitivanja tijekom dvije godine na četiri lokacije u Republici Hrvatskoj (Lovas, Osijek, Kutjevo, Zagreb). U pokusima standardne sorte bile su Srpanjka, Žitarka i Divana. Sorta Bc Mandica postigla je za 26,2\% veći urod zrna od Srpanjke, za $19 \%$ veći urod zrna od Žitarke i za $40 \%$ u odnosu na Divanu. Najveći urod zrna od $10.047 \mathrm{~kg} / \mathrm{ha}, \mathrm{Bc}$ Mandica ostvarila je 2012. godine na lokaciji Zagreb gdje je i kreirana.

Prema genetskom potencijalu za urod zrna, prosječnom urodu zrna i stabilnosti u navedenom svojstvu, sorta Bc Mandica može se širiti na svim žitorodnim područjima naše zemlje.

Ispitivanja sorti strnih žitarica u mreži makropokusa Bc Instituta d.d. omogućuje izbor najrodnijih genotipova za određeno proizvodno područje. Nove komercijalne $\mathrm{Bc}$ sorte ozime pšenice tijekom 2013./2014. godine ispitane su u komparativnim makropokusima na četiri lokacije: Donja Dubrava, Rugvica, Staro Topolje i Koška (Tablica 5).

Sorta Bc Mandica postigla je prosječni urod zrna od $8.385 \mathrm{~kg} / \mathrm{ha}$ i po rangu uroda zauzima prvo mjesto. Pojedinačno najveći urod zrna od $9.370 \mathrm{~kg} / \mathrm{ha}$ novopriznata sorta postigla je na lokaciji Staro Topolje. 
R. Mlinar i sur: Bc Mandica - nova sorta ozime pšenice

Tablica 5. Urod (kg/ha) Bc sorti ozime pšenice u makropokusima 2013./2014. godine Table 5 Grain yield ( $\mathrm{kg} / \mathrm{ha}$ ) of Bc winter wheat varieties in macrotrials in 2013/2014

\begin{tabular}{|c|c|c|c|c|c|}
\hline \multirow{2}{*}{$\begin{array}{l}\text { Sorta } \\
\text { Variety }\end{array}$} & \multicolumn{4}{|c|}{ Lokacije - Locations } & \multirow{2}{*}{$\begin{array}{l}\text { Prosjek } \\
\text { Average }\end{array}$} \\
\hline & $\begin{array}{c}\text { DONJA } \\
\text { DUBRAVA }\end{array}$ & RUGVICA & $\begin{array}{c}\text { STARO } \\
\text { TOPOLJE }\end{array}$ & KOŠKA & \\
\hline Bc Mandica & 6.959 & 8.610 & 9.370 & 8.600 & 8.385 \\
\hline Bc Anica & 8.172 & 8.068 & 7.822 & 8.382 & 8.111 \\
\hline Bc Darija & 7.703 & 8.188 & 7.692 & 8.326 & 7.977 \\
\hline Bc Certissa & 6.134 & 8.192 & 7.781 & 8.401 & 7.627 \\
\hline Bc Lorena & 6.512 & 8.356 & 7.901 & 7.634 & 7.601 \\
\hline Bc Irma & 6.462 & 8.132 & 8.086 & 7.634 & 7.579 \\
\hline Bc Mira & 6.732 & 7.251 & 7.690 & 8.430 & 7.526 \\
\hline Prima & 7.742 & 7.044 & 7.619 & 7.694 & 7.525 \\
\hline Bc Bernarda & 6.432 & 7.754 & 7.058 & 8.619 & 7.466 \\
\hline Mihelca & 7.593 & 7.606 & 7.450 & 7.126 & 7.444 \\
\hline Bc Lira & 6.621 & 7.757 & 7.295 & 8.090 & 7.441 \\
\hline Dora & 6.214 & 7.250 & 7.441 & 7.916 & 7.205 \\
\hline Bc Renata & 5.636 & 7.089 & 8.636 & 7.446 & 7.202 \\
\hline $\mathrm{Bc}$ Irena & 6.967 & 6.940 & 6.289 & 6.967 & 7.019 \\
\hline Bc Tena & 6.134 & 7.367 & 6.963 & 7.142 & 6.902 \\
\hline $\begin{array}{l}\text { Prosjek } \\
\text { Average }\end{array}$ & 6.801 & 7.707 & 7.673 & 7.894 & 7.534 \\
\hline
\end{tabular}

\section{Fizička i prerađivačka svojstva zrna}

Sorta Bc Mandica je krupnozrna i ima visoku vrijednost mase 1.000 zrna koja u prosjeku iznosi 44,6 g. Hektolitarska masa, važan parametar u određivanju mlinarskih vrijednosti pšenice koja se od davnina koristi kao osnovni pokazatelj kvalitete zrna, kod Bc Mandice iznosi 74,1 kg/hl. Meljava pšenice je sukcesivno selektivan postupak usitnjavanja zrna, a izbrašnjavanje predstavlja količinu brašna koja se dobiva od $100 \mathrm{~kg}$ samljevene pšenice. Izbrašnjavanje se u većini zemalja kreće u granicama od 73 do $78 \%$. U nekim zemljama koje ne proizvode dovoljno pšenice nivo izbrašnjavanja iznosi oko $80 \%$ (Ž ě̌ elj, 1989). Prosječno izbrašnjavanje, bez otresivača, sorte Bc Mandica iznosilo je 75,7\%. Prema tome, zrno Bc Mandice vrlo je povoljno za preradu (Tablica 6). 
Tablica 6. Kvalitetna svojstva sorte pšenice Bc Mandica - prosječne vrijednosti lokacija Osijek i Zagreb, 2012. godina. (Pokusi Komisije za priznavanje sorata Republike Hrvatske)

Table 6 Quality parameters of wheat variety Bc Mandica. Mean values, experiment at Osijek and Zagreb, year 2012 (Experiments of the Croatian Committee for Registration of Agricultural Crop Varieties)

\begin{tabular}{lc}
\hline Svojstva - Characteristics & Sorta - Variety \\
\cline { 2 - 2 } $\begin{array}{l}\text { Proteini (\%) } \\
\text { Protein content (\%) }\end{array}$ & Bc Mandica \\
\hline $\begin{array}{l}\text { Sedimentacija (ml) } \\
\text { Sedimentation value (ml) }\end{array}$ & 21,77 \\
\hline $\begin{array}{l}\text { Vlažni gluten (\%) } \\
\text { Wet gluten (\%) }\end{array}$ & 30,58 \\
\hline $\begin{array}{l}\text { Izbrašnjavanje (\%) } \\
\text { Flour extraction (\%) }\end{array}$ & 77,05 \\
\hline $\begin{array}{l}\text { Broj padanja (sek) } \\
\text { Falling number (sec) }\end{array}$ & 355 \\
\hline $\begin{array}{l}\text { Upijanje vode (\%) } \\
\text { Water absor. (\%) }\end{array}$ & 58,2 \\
\hline $\begin{array}{l}\text { Razvoj tijesta (min) } \\
\text { Dough devel. time (min) }\end{array}$ & 2,8 \\
\hline $\begin{array}{l}\text { Stabilitet (min) } \\
\text { Stability (min) }\end{array}$ & 1,6 \\
\hline $\begin{array}{l}\text { Rezistencija (min) } \\
\text { Resistance (min) }\end{array}$ & 4,4 \\
\hline $\begin{array}{l}\text { Stupanj omekšanja (FJ) } \\
\text { Degree of softening (FU) }\end{array}$ & 87 \\
\hline $\begin{array}{l}\text { Kvalitetni broj } \\
\text { Quality number }\end{array}$ & 57,3 \\
\hline $\begin{array}{l}\left.\text { Energija (cm }{ }^{2}\right) \\
\text { Energy (cm }{ }^{2}\end{array}$ & 61,4 \\
\hline $\begin{array}{l}\text { Rastezljivost (mm) } \\
\text { Extensibility (mm) }\end{array}$ & 162 \\
\hline $\begin{array}{l}\text { Otpor (EJ) } \text { Resistance (EU) } \\
\text { Maksimalni otpor (EJ) } \\
\text { Max. resistance (EU) }\end{array}$ & 207 \\
\hline $\begin{array}{l}\text { Odnos (O/R) } \\
\text { Ratio E/R }\end{array}$ & 280 \\
\hline $\begin{array}{l}\text { Kvalitetna grupa } \\
\text { Quality subclass }\end{array}$ & 1,27 \\
\hline & \\
\hline
\end{tabular}

\section{Kemijski sastav - klasifikacija}

Sadržaj proteina pšenice varira u prilično širokom intervalu (od 6 do 18\%) ovisno o okolinskim i genetskim čimbenicima. Općenito, kako se povećava sadržaj proteina, smanjuje se sadržaj škroba (Mark ovi ć, 2012). Kod sorte Bc Mandica sadržaj proteina u prosjeku dviju lokacija iznosio je 11,77\% (Tablica 6). 
Za brzo utvrđivanje kvalitete zrna i brašna pšenice pribjegava se indirektnim metodama koje su neusporedivo brže od direktnih metoda kod kojih se fizička svojstva tijesta ocjenjuju specijalnom reološkom opremom. Od indirektnih pokazatelja najčešće se koristi sedimentacijska vrijednost po Zeleny-u. Prosječna sedimentacijska vrijednost brašna sorte Bc Mandica s lokacije Osijek i Zagreb iznosila je 28,58 ml.

Količina i kvaliteta proteina glutena utječe na viskozno-elastična svojstva tijesta. Drugim rječima, što je veća količina i kvaliteta vlažnog glutena dobit ćemo dovoljno rastezljivo i elastično tijesto koje tijekom fermentacije zadržava plin i osigurava dobar volumen i dobar raspored šupljina nekog pekarskog proizvoda. Sorta Bc Mandica ima visok potencijal za stvaranje vlažnog glutena, koji u prosjeku ima vrijednost 30,25\%.

Promatrajući svojstva tijesta pri zamjesu, moć upijanja vode u prosjeku je iznosila $58,2 \%$, razvoj tijesta 2,8 min, rezistencija 4,4 min, a stupanj omekšanja 87 FJ. Prosječna vrijednost kvalitetnog broja iznosila je 57,3 te se sorta Bc Mandica svrstava u B1 kvalitetnu grupu. Prosječna energija tijesta kao jednog od ekstenzografskih pokazatelja sa dvije lokacije kod sorte Bc Mandica iznosila je $61,4 \mathrm{~cm}^{2}$. Analiza pokazuje da sorta Bc Mandica u toku obrade daje tolerantna i stabilna tijesta, a nakon pečenja kvalitetne pekarske proizvode (Tablica 6).

\section{ZAKLJUČAK}

Bc Institutu d.d. 2014. godine priznata je nova sorta ozime pšenice Bc Mandica. Sorta je nastala križanjem eksperimentalne linija 187188 i sorte Feniks. U dvogodišnjim službenim ispitivanjima na više lokacija Republike Hrvatske imala je znatno veći urod zrna u odnosu na standardne sorte ozime pšenice Srpanjke, Žitarke i Divane. Bc Mandica je srednje rana sorta, ima visinu stabljike oko $85 \mathrm{~cm}$. Sorta pripada B1 kvalitetnoj grupi. Posjeduje povoljno uravnoteženu otpornost prema najvažnijim bolestima pšenice, posebno prema lisnoj pjegavosti. Imajući u vidu sva biološkotehnoloških svojstva može se očekivati brzo širenje nove sorte $\mathrm{Bc}$ Mandice na našem žitorodnom području.

\section{Bc MANDICA-A NEW Bc WINTER WHEAT VARIETY}

\section{SUMMARY}

In 2014 a new winter wheat variety developed by the Bc Institute, Bc Mandica, was released. Bc Mandica belongs to species Triticum aestivum L. emend Fiori et Paol. var. Lutescens Al, it has white awnless ears and red grains. Average yield of the Bc Mandica in official trials conducted by the Croatian Centre for Agriculture, Food and Rural Affairs - Institute for Seed 
and Seedlings was $8.438 \mathrm{~kg} / \mathrm{ha}$ and, it outyielded all three standard winter wheat varieties Srpanjka, Žitarka and Divana. After successful registration procedure, Bc Mandica was enlisted to the List of Varieties of the Republic of Croatia in 2014. In regard to the growth season Bc Mandica could be classified as middle early. It achieves stabile and exceptionally high yield and, according to quality parameters of grain, flower and dough, it belongs to the B1 quality group.

Key words: wheat, variety, grain yield, quality

\section{LITERATURA- REFERENCES}

1. Borojević, S., Potočanac, J.(1966): Izgradnja Jugoslavenskog programa stvaranja visokoprinosnih sorti pšenice. V jugoslavenski simpozij o naučno-istraživačkom radu na pšenici. Savremena poljoprivreda, $11-12: 7-35$.

2. Borojević, S. (1986): Genetic change in morphophysiological characters in relation to breeding for increased wheat yield. In F.L. Smith (Ed.), Genetics Improvementin Yield of Wheat. CSSA Spac. Pub. 13: 71-85.

3. Jošt, M., Samobor, V. Vukobratović, M. (2006). Oplemenjivanje pšenice za posebnu namjenu. Glasnik zaštite bilja. 1: $42-47$.

4. Mark ović, M. (2012). Tehnologija hrane. Sastav pšeničnog brašna http://www.tehnologijahrane.com/tehnologija-mlinarstvo-i-mlinarstvo/sastav-psenicnog-brasna. 8. listopad 2013.

5. Potočanac, J. (1966). Vuka - domaća visokorodna sorta pšenice. Savremena poljoprivreda. 4: 307-321.

6. Tomas ovi ć, S., Mlin ar, R., Ik ić, I., Ju ki ć, K. (2012). Oplemenjivanje pšenice i pšenoraži u Bc Institutu d.d. Zagreb. u Oplemenjivanje poljoprivrednog bilja u Hrvatskoj, (ur) Kozumplik, Pejić. Udžbenici Sveučilišta u Zagrebu, 4.1: 43- 47.

7. Ž Žželj, M. (1989). Tehnologija i oprema za preradu žita. Naučna knjiga, Beograd, IRO "Naučna knjiga" Beograd: 173-194.

Adresa autora - Author's address:

Mr.sc. Rade Mlinar

Dr. sc. Ivica Ikić

Dr. sc. Katarina Jukić

Marko Maričević, mag. ing. agr.

Dr. sc. Miroslav Bukan

Bc Institut za oplemenjivanje i proizvodnju bilja d.d.

Rugvica, Dugoselska 7,

10370 Dugo Selo

E-mail: bc-botinec@bc-institut.hr
Primljeno - Received:

08. 12. 2014. 
